\title{
Downregulation of Blimp1 inhibits the maturation of bone marrow-derived dendritic cells
}

\author{
JIANSHENG XIAO ${ }^{1-5^{*}}, \mathrm{JI}_{\mathrm{ZHANG}}{ }^{2-5^{*}}, \mathrm{XING} \mathrm{LI}^{2-6}, \mathrm{XIAOMIN} \mathrm{DAI}^{2-5}, \mathrm{JING}_{\mathrm{WANG}}^{2-5}$, \\ YING $\mathrm{HE}^{2-5}$, LAI WEI ${ }^{2-5}$, JUN SHI ${ }^{1-5}$ and NIANQIAO GONG ${ }^{2-5}$ \\ ${ }^{1}$ Department of Hepatobiliary and Organ Transplantation Surgery, The First Affiliated Hospital of Nanchang University, \\ Nanchang, Jiangxi 330006; ${ }^{2}$ Institute of Organ Transplantation, Tongji Hospital, Tongji Medical College, \\ Huazhong University of Science and Technology; ${ }^{3}$ Key Laboratory of Organ Transplantation, Ministry of Education; \\ ${ }^{4}$ Chinese National Health Commission (NHC) Key Laboratory of Organ Transplantation; ${ }^{5}$ Key Laboratory of \\ Organ Transplantation, Chinese Academy of Medical Sciences; ${ }^{6}$ Department of General Surgery, \\ The Eighth Hospital of Wuhan, Wuhan, Hubei 430030, P.R. China
}

Received April 26, 2018; Accepted November 21, 2018

DOI: $10.3892 /$ ijmm.2018.4000

\begin{abstract}
Modulation of differentiation of dendritic cells (DCs), which are derived from bone marrow cells, may influence their maturation and consequently regulate their ability to present antigens to alloreactive $\mathrm{T}$ lymphocytes. B lymphocyte-induced maturation protein-1 (Blimp1) is a master regulator of immunocyte differentiation, which has been investigated for its effect on DCs. In the present study, a lentivirus was used as a vector to transduce Blimp1-short hairpin (sh)RNA into primary bone marrow cells during their differentiation to DCs. Lentiviral-mediated Blimp1-shRNA (lenti-shRNA-Blimp1) had a transduction efficiency of $>60 \%$ in DC precursors. Lenti-shRNA-Blimp1 significantly downregulated the expression levels of Blimpl and modulated the expression of its target proteins, including class II major histocompatibility complex (MHC) transactivator, c-myc and interleukin-6. Although lenti-shRNA-Blimp1 did not interfere with the differentiation of bone marrow cells to DCs, it inhibited DC maturation by decreasing the expression of surface MHC-II molecules, but not the expression of MHC-I molecules and co-stimulatory molecules [cluster of differentiation (CD)80/CD86]. Subsequently, alloreactive
\end{abstract}

Correspondence to: Dr Nianqiao Gong or Dr Jun Shi, Institute of Organ Transplantation, Tongji Hospital, Tongji Medical College, Huazhong University of Science and Technology, 1095 Jie Fang Avenue, Wuhan, Hubei 430030, P.R. China

E-mail: nqgong@tjh.tjmu.edu.cn

E-mail:shijundoc@yahoo.com

*Contributed equally

Keywords: lentiviral vector, B lymphocyte-induced maturation protein-1, dendritic cells, differentiation, maturation, alloreactive $\mathrm{T}$ cell activation
$\mathrm{T}$ cell proliferation was alleviated and regulatory $\mathrm{T}$ cells were expanded in response to lenti-shRNA-Blimp1. A toxicity assay indicated that the morphology and proliferation of cultured DCs were mildly influenced by the lentiviral vector, indicating that the use of alternative vectors with minimal or no toxicity could be investigated in future studies. In conclusion, transduction with lenti-shRNA-Blimp1 modulated the maturation of DCs via MHC-II molecule suppression and inhibited alloreactive T cell activation. The present findings supported the application of Blimp1-based intervention as a novel approach to induce immature DCs for further immunological research.

\section{Introduction}

Dendritic cells (DCs) are commonly derived from the bone marrow, spleen, lymph glands and peripheral blood. The conventional and stable method for obtaining DCs is the cultivation and differentiation of DC precursors (pre-DCs), which are derived from the primary cells of the bone marrow (1). DCs serve pivotal roles in the immune response. Immature DCs exhibit potent antigen-uptake and weak antigen-presenting activities, whereas mature DCs possess weak antigen-uptake and potent antigen-presenting activities (2).

B lymphocyte-induced maturation protein-1 (Blimp1) is a transcriptional inhibitor with five zinc finger motifs that is known to act as a master regulator of B-cell terminal differentiation. Blimp1 modulates plasmocyte differentiation $(3,4)$, and regulates the development and stability of $\mathrm{T}$ cells, including $\mathrm{T}$ helper cells and regulatory $\mathrm{T}$ cells (Tregs) $(5,6)$. In addition, Blimp1 modulates lipopolysaccharide (LPS)-induced differentiation of primary B lymphocytes (7), induces the differentiation of macrophages (8) and affects the maturation of DCs by regulating various signaling cascades (9). Furthermore, it affects stem cell development and tissue formation by regulating sagittal axis development and head structure formation $(10,11)$. Although the basal expression of Blimp1 is low in bone marrow-derived DCs, Blimp1 serves a critical role in the tolerogenic function of DCs; diminished 
Blimp1 expression in DCs can result in aberrant activation of the adaptive immune system (12-14), which may be associated with DC differentiation and maturation.

Genetic manipulation is a notable method for modulating the function of target cells. Each vector, non-viral or viral, has distinct features. Although the liposome method is conventional and cheap, it has low efficiency in primary and/or non-dividing cells, and can alter the expression of certain genes by affecting the physiological function of cells (15). Although electroporation has high transfection efficiency, it causes severe cell damage. Adenoviral vectors have high efficiency during cell infection, but can lead to immune responses due to their immunogenicity $(16,17)$. Lentiviral vectors have the ability to efficiently transduce non-dividing and dividing cells by inserting a large genetic segment in the host chromatin, in order to sustain stable long-term transgene expression. Furthermore, lentiviral vectors can be used to generate the induction of pluripotent stem cells $(18,19)$. Lentiviruses have recently been accepted as promising transduction vectors for stem cells (20). Their applications have been examined in bone marrow cells, which contain numerous stem cells and precursor cells, which possess the potential to differentiate into a wide range of cells (21).

Based on previous studies, it was hypothesized that lentiviral-mediated Blimp1 short hairpin RNA (shRNA) (lenti-shRNA-Blimp1) gene transduction may affect the differentiation and maturation of DCs, and consequently regulate subsequent antigen presentation to $\mathrm{T}$ cells. In the present study, primary bone marrow cells were harvested from mice and the cells were transduced with lenti-shRNA-Blimp1. During the differentiation of pre-DCs to DCs, transduction efficiency, and the mRNA and protein expression levels of Blimp1 were assessed. The effects of Blimp1 downregulation on differentiation, maturation and alloreactive $\mathrm{T}$ cell stimulation of DCs were also elucidated. In addition, the disadvantages of this method were identified. The findings of the present study may aid the establishment of a novel model for generating immature DCs from marrow-derived cells, in order to regulate immune reactions.

\section{Materials and methods}

Animals. Male C57BL/6 and BALB/C mice (weight, 20 g; age, 6-8 weeks) were purchased from Beijing HFK Bioscience Co. Ltd. (Beijing, China) and were maintained under specific pathogen-free conditions (humidity, 50-60\%; temperature, $18-22^{\circ} \mathrm{C} ; 12-\mathrm{h}$ light/dark cycle; free access to food and water). Six C57BL/6 mice were used for reverse transcription-quantitative polymerase chain reaction (RT-qPCR). Six C57BL/6 mice were used for western blotting. Six C57BL/6 mice and two BALB/C mice were used for mixed lymphocyte reaction (MLR). Six C57BL/6 mice were used for ELISA and flow cytometry. All experiments were approved by the Institutional Animal Care and Use Committee at Tongji Medical College, Huazhong University of Science and Technology (Wuhan, China; ethical approval no. TJ-A201111211).

Culture of DCs. The culture of DCs from mouse bone marrow cells has been reported previously (22-25). Briefly, the femurs and tibiae of male C57BL/6 mice were removed, purified and maintained in RPMI 1640 (cat. no. SH30809.01B; HyClone; GE Healthcare, Logan, UT, USA) supplemented with $10 \%$ inactivated fetal bovine serum (FBS; cat. no. 16000044; Gibco; Thermo Fisher Scientific, Inc., Waltham, MA, USA). Both ends were then cut and the bone marrow was flushed. The clusters within the marrow suspension were disintegrated by vigorous pipetting and the red blood cells were lysed using red blood cell lysis buffer (cat. no. R1010; Beijing Solarbio Science \& Technology Co., Ltd., Beijing, China). Approximately $1-1.5 \times 10^{7}$ bone marrow-derived mononuclear cells (BMDMCs) were obtained per femur and/or tibia. On day $0,1 \times 10^{6}$ BMDMCs were added to each well (6-well plate) in $2.5 \mathrm{ml}$ medium consisting of complete RPMI 1640, $20 \mathrm{ng} / \mathrm{ml}$ recombinant mouse ( $\mathrm{rm})$ granulocyte-macrophage colony-stimulating factor (GM-CSF; cat. no. 315-03) and $10 \mathrm{ng} / \mathrm{ml} \mathrm{rm}$ interleukin (IL)-4 (cat. no. cat. no. 214-14; both PeproTech, Inc., Rocky Hill, NJ, USA). On day 3, the medium containing non-adherent cells was discarded and $2.5 \mathrm{ml}$ fresh medium with supplemented GM-CSF and IL-4 was added for further culture. On day 6 , the medium containing non-adherent cells was collected and centrifuged at $300 \mathrm{x}$ g for $5 \mathrm{~min}$ at $25^{\circ} \mathrm{C}$. The cell pellet was resuspended and incubated in $2.5 \mathrm{ml}$ RPMI 1640 supplemented with 10\% inactivated FBS (25-28). On day 7, 500 ng/ml LPS (cat. no. L2630; Sigma-Aldrich; Merck KGaA, Darmstadt, Germany) was added to the culture for $24 \mathrm{~h}$, in order to induce DC maturation. On day 8, cell culture was terminated and the cells were harvested for further investigation. The morphology and proliferation of cultured cells were observed and recorded under a microscope (Nikon Eclipse TE2000-E; Nikon Corporation, Tokyo, Japan).

Design and synthesis of shRNA. The shRNA sequence that was designed for Blimp1 interference was 5'-GGAAAGGAC CUCUACCGUUTT-3' (29). The negative control shRNA sequence was 5'-TTCTCCGAACGTGTCACGT-3'. The loop structure in the shRNA template was selected as TTCAAG AGA, in order to avoid the termination signal, and the shRNA sequence of transcriptional termination was selected as the T6 structure. The CACC sequence was added at the 5'-end in the sense strand, which could combine with the sticky end of $B b s \mathrm{I}$, which was produced by enzyme digestion. The GATC sequence was added at the 5'-end in the antisense strand, which could combine with the sticky end of BamHI, which was produced by enzyme digestion. DNA oligos (shRNA sequences) were dissolved in TE ( $\mathrm{pH}$ 8.0) solution at a concentration of $100 \mu \mathrm{M}$. PCR amplification was used to complete the annealing process and the products were preserved at $4^{\circ} \mathrm{C}(30)$. The shRNA samples were obtained following the annealing process. Their concentration was $10 \mu \mathrm{M}$ and they were diluted 500 times to a final concentration of $20 \mathrm{nM}$, which was used for ligation.

Construction of lentiviral vectors. The shRNA was ligated into the pGPU6/GFP/Neo vector to establish the pGPU6/GFP/Neo-shRNA vector. The green fluorescent protein (GFP) gene uses a separate CMV promoter, which is different from the U6 promoter. For transformation, shRNA vectors (100 ng) were mixed with $50 \mu 1$ Escherichia coli (TOP10; Invitrogen; Thermo Fisher Scientific, Inc.) and incubated in LB culture medium containing $10 \mathrm{~g}$ 
tryptone, $5 \mathrm{~g}$ yeast extract and $5 \mathrm{~g}$ sodium chloride per 11 (cat. nos. LP0042B, LP0021T and LP0005B; Thermo Fisher Scientific, Inc.) at $37^{\circ} \mathrm{C}$ for $90 \mathrm{~min}$ with constant agitation at $200 \mathrm{rpm}$. Five positive transformant colonies were selected on LB agar plates (cat. no. 22700041; Invitrogen; Thermo Fisher Scientific, Inc.) containing $50 \mu \mathrm{g} / \mathrm{ml}$ kanamycin (cat. no. E004000; Sigma-Aldrich; Merck KGaA) following incubation at $37^{\circ} \mathrm{C}$ for $14 \mathrm{~h}$. The pGPU6/GFP/Neo-shRNA vector plasmids were extracted using the alkaline lysis method and were identified by BamHI and Pst I enzyme digestion. Subsequently, $9 \mu \mathrm{g}$ lentiviral packaging plasmid (Virapower ${ }^{\mathrm{TM}}$ Packaging Mix; cat. no. K497500; Thermo Fisher Scientific, Inc.) and $3 \mu \mathrm{g}$ lentiviral vector were each diluted in $1.5 \mathrm{ml}$ Opti-minimum essential medium (MEM) culture medium (cat. no. SH30024.01; HyClone; GE Healthcare). The two components were then mixed. Typically, $36 \mu$ l Lipofectamine ${ }^{\circledR} 2000$ (Invitrogen; Thermo Fisher Scientific, Inc.) was diluted in $1.5 \mathrm{ml}$ Opti-MEM culture medium and was then mixed with the viral vector dilution after $5 \mathrm{~min}$. The mixture was incubated for $20 \mathrm{~min}$ at room temperature and was then transfected into 293 T cells (CRL-3216; American Type Culture Collection, Manassas, VA, USA), which were cultured in high-glucose Dulbecco's Modified Eagle's Medium (cat. no. SH30022.01B; HyClone, GE Healthcare) supplemented with $10 \%$ inactivated FBS (cat. no. 16000044; Gibco; Thermo Fisher Scientific, Inc.) for $24 \mathrm{~h}$ at $37^{\circ} \mathrm{C}$ in an atmosphere containing $5 \% \mathrm{CO}_{2}$ and $95 \%$ humidity. The supernatant containing the virus was collected between 48 and $72 \mathrm{~h}$ post-transfection and was centrifuged at $300 \mathrm{x} \mathrm{g}$ for $5 \mathrm{~min}$ at $4^{\circ} \mathrm{C}$. The cellular debris was removed using Lenti- $\mathrm{X}^{\mathrm{TM}}$ Maxi Purification kit (cat. no. 631233; Takara Bio Inc., Otsu, Japan) and viruses were preserved at $-80^{\circ} \mathrm{C}$. The viral titer was detected in the $293 \mathrm{~T}$ cell line. Positive colonies were selected, and the lentiviral titer was calculated by crystal violet staining.

Lentiviral transduction of bone marrow cells. On culture day 1 , the lentiviral solution $\left(1 \times 10^{9} \mathrm{TU} / \mathrm{ml}\right)$ was thawed at $37^{\circ} \mathrm{C}$ and added to the cultures ( $\left.80 \mu \mathrm{l} / \mathrm{well}, 8 \times 10^{7} \mathrm{TU}\right)$ at a multiplicity of infection of 100 . Furthermore, polybrene was added at a final concentration of $5 \mu \mathrm{g} / \mathrm{ml}$. On day 2 , the medium was replaced to remove the residual virus, and cells were incubated with $20 \mathrm{ng} / \mathrm{ml} \mathrm{GM-CSF}$ and $20 \mathrm{ng} / \mathrm{ml} \mathrm{IL-4.}$

Grouping. According to lentiviral transduction, cultured cells were divided into the following three groups: Empty-control group, in which the cells received no intervention; lenti-control group, in which the cells received blank lentiviral transduction; and lenti-shRNA-Blimpl group, in which cells received lenti-shRNA-Blimp1-shRNA transduction.

Detection of mRNA expression by RT-qPCR. A total of $72 \mathrm{~h}$ post-transduction, total RNA was extracted from the immature cells in each group using TRIzol ${ }^{\circledR}$ (cat. no. 15596018; Invitrogen; Thermo Fisher Scientific, Inc.) and RNA concentration was adjusted to $1 \mathrm{~g} / \mathrm{l}$. $\beta$-actin, which is a housekeeping gene for normalization, served as an internal reference. The primers used for detection of the corresponding gene transcripts were as follows: $\beta$-actin (accession no. NC_000071) forward, 5'-AGTGTGACGTTGACATCC GTA-3' and reverse, 5'-GCCAGAGCAGTAATCTCCT
TCT-3'; Blimp1 (accession no. NC_000076) forward, 5'-GTA TTGTCGGGACTTTGCGGAG-3' and reverse, 5'-TCACTA CTGTATTGCTTTGGGTTGC-3'; class II major histocompatibility complex (MHC) transactivator (CIITA) (accession no. NC_000082) forward, 5'-TGCAGGCGACCAGGAGAG ACA-3' reverse, 5'-GAAGCTGGGCACCTCAAAGAT-3'; and c-myc (accession no. NC_000081) forward, 5'-CACCAG CAGCGACTCTGAA-3' and reverse, 5'-GCCCGACCTC TTG-3'. Total RNA was reverse transcribed into cDNA using the PrimeScript ${ }^{\mathrm{TM}}$ RT reagent kit (Perfect Real Time; cat. no. RR036A; Takara Bio Inc.), according to manufacturer's protocol, which was then used as a template for PCR amplification. qPCR was conducted using TransStart Top Green qPCR SuperMix (+Dye I) (cat. no. AQ132-11; Beijing TransGen Biotech Co., Ltd., Beijing, China), with the following reaction conditions: Pre-denaturation at $95^{\circ} \mathrm{C}$ for $1 \mathrm{~min}$, followed by 40 cycles of denaturation at $95^{\circ} \mathrm{C}$ for $15 \mathrm{sec}$, annealing at $58^{\circ} \mathrm{C}$ for $20 \mathrm{sec}$ and extension at $72^{\circ} \mathrm{C}$ for $20 \mathrm{sec}$, and a final extension step at $72^{\circ} \mathrm{C}$ for $5 \mathrm{~min}$. Relative quantity (RQ) was used to determine the mRNA expression levels, according to melting curve analysis. The detection was performed in triplicate (31).

Detection of protein expression by western blotting. Blimp1, and its direct target proteins CIITA and c-myc, were examined by western blotting. A total of $96 \mathrm{~h}$ post-transduction, the immature cells in each group were lysed in lysis buffer (cat. no. P0013; Beyotime Institute of Biotechnology, Shanghai, China) and the total protein was quantified as previously described $(32,33)$. The protein concentration was adjusted to $1.5 \mathrm{~g} / 1$ and the proteins were stored at $-80^{\circ} \mathrm{C}$. Subsequently, $30 \mu \mathrm{g}$ proteins were loaded per lane, separated by $10 \%$ SDS-PAGE, subjected to electrophoresis ( $80 \mathrm{~V}$ for $30 \mathrm{~min}$ and $110 \mathrm{~V}$ for $30 \mathrm{~min}$ ) and electrotransferred onto a polyvinylidene fluoride membrane at a constant current of $200 \mathrm{~mA}$ for $150 \mathrm{~min}$. The membrane was blocked with nonfat milk for $2 \mathrm{~h}$ at $37^{\circ} \mathrm{C}$ in order to reduce nonspecific binding, and was then incubated with the following primary antibodies (1:500) at $4^{\circ} \mathrm{C}$ overnight: Blimp1 (cat. no. 9115; Cell Signaling Technology, Inc., Danvers, MA, USA), CIITA (cat. no. sc-13556; Santa Cruz Biotechnology, Inc., Dallas, TX, USA) and c-myc (cat. no. 5605; Cell Signaling Technology, Inc.). Subsequently, the membrane was washed three times in Tris-buffered saline-0.1\% Tween-20 (15 min/wash) and incubated with secondary antibodies (1:6,000; cat. nos. A0216 and A0208; Beyotime Institute of Biotechnology) at $37^{\circ} \mathrm{C}$ for $1.5 \mathrm{~h}$. The membrane was then treated with enhanced chemiluminescence reagents (cat. no. P0018AM; Beyotime Institute of Biotechnology), in order to visualize the bands, which were scanned and densitometrically analyzed by ImageJ 1.6.0_20 (National Institutes of Health, Bethesda, MD, USA). Densitometric values were normalized to $\beta$-actin (1:1,000; cat. no. 3700; Cell Signaling Technology, Inc.) immunoreactivity, in order to correct for loading and transfer differences among the samples. The detection procedure was repeated in triplicate.

ELISA. The concentration levels of a direct target of Blimp1, IL-6, were detected in the culture supernatant on culture day 7 by ELISA. The IL-6 ELISA kit (cat. no. DKW12-2060-096; Dakewe Biotech Co., Ltd., Shenzhen, China) was used 
according to the manufacturer's protocol. The detection was repeated in triplicate.

$M L R$. Lymph nodes from BALB/C mice were harvested from the armpits, groin and mesenteric lymph nodes. Lymph nodes were minced and filtered through a $70-\mu \mathrm{m}$ cell strainer (cat. no. 352350; BD Biosciences, Franklin Lakes, NJ, USA) to obtain alloreactive $\mathrm{T}$ cells $(22,34-36)$. Total $\mathrm{T}$ cells were stained with $2 \mu \mathrm{M}$ PKH26 (cat. no. MINI26; Sigma-Aldrich; Merck $\mathrm{KGaA}$ ) at room temperature for $5 \mathrm{~min}$. On day 8 , the transduced C57BL/6 DCs were harvested and co-cultured with $10^{5}$ alloreactive T cells at a ratio of 1:5 in 96-well round-bottom plates in triplicate; non-transduced C57BL/6 DCs were used as a control. After $96 \mathrm{~h}$ incubation at $37^{\circ} \mathrm{C}, 5 \% \mathrm{CO}_{2}$ and $95 \%$ humidity, $\mathrm{T}$ cell proliferation was measured by flow cytometry. T cells that were cultured with non-stimulated DCs were used as a negative control. As a positive control, at the beginning of MLR, T cells were stimulated by cluster of differentiation (CD)3 and CD28 antibodies (1:2,000; cat. nos. 16-0032-85 and 16-0281-85; eBiosciences; Thermo Fisher Scientific, Inc.) at $37^{\circ} \mathrm{C}$ for $96 \mathrm{~h}$.

Flow cytometry. At the end of DC culture, the cells in each group were centrifuged at $300 \mathrm{x}$ g for $5 \mathrm{~min}$. The supernatant was removed and the cells were washed with PBS (cat. no. SH30256.01B; HyClone; GE Healthcare) containing $0.5 \%$ bovine serum albumin (cat. no. B2064; Sigma-Aldrich; Merck $\mathrm{KGaA}$ ) at room temperature for $5 \mathrm{~min}$, after which they were incubated with anti-mouse CD11c, CD80, CD86, MHC-I and MHC-II antibodies (1:100; cat. nos. 17-0114-82, 17-0801-82, 12-0860-83, 17-5958-82 and 12-0920-82; eBiosciences; Thermo Fisher Scientific, Inc.) in the dark at $4^{\circ} \mathrm{C}$ for $30 \mathrm{~min}$. Subsequently, the cells were centrifuged at $300 \mathrm{x} \mathrm{g}$ for $5 \mathrm{~min}$ at $4^{\circ} \mathrm{C}$, resuspended in $1 \mathrm{ml} \mathrm{PBS}$, and analyzed by flow cytometry and FlowJo 7.6 (FlowJo LLC, Ashland, OR, USA). Alloreactive T cells were collected at the end of MLR and were stained with a CD4 antibody (cat. no. 45-0042-82; eBiosciences; Thermo Fisher Scientific, Inc.) in $1 \mathrm{ml} \mathrm{PBS}$ in the dark at $4^{\circ} \mathrm{C}$ for $30 \mathrm{~min}$. With regards to intracellular staining, the cells were fixed and permeabilized with Fixation \& Permeabilization Buffer (cat. no. 88-8824-00; eBiosciences; Thermo Fisher Scientific, Inc.) at $4^{\circ} \mathrm{C}$ for $30 \mathrm{~min}$, stained with forkhead box P3 (Foxp3) antibodies (1:50; cat. no. 17-5773-82; eBiosciences; Thermo Fisher Scientific, Inc.) at $4^{\circ} \mathrm{C}$ for $30 \mathrm{~min}$, and were then analyzed by flow cytometry. All antibodies were diluted in PBS. Forward scatter and side scatter were employed to gate the lymphocytes and exclude other types of cells. Green fluorescence was detected in cells by flow cytometry using the 530/40 filter (GFP); these cells were defined as $\mathrm{GFP}^{+}$cells. The proportion of $\mathrm{CD}_{1} 1^{\mathrm{c}+}, \mathrm{CD}^{+} 0^{+}$, $\mathrm{CD}^{+} 6^{+}, \mathrm{MHC}^{-} \mathrm{I}^{+}, \mathrm{MHC} \mathrm{II}^{+}, \mathrm{CD}^{+}, \mathrm{Foxp}^{3+}$ and $\mathrm{GFP}^{+}$cells was estimated. Mean fluorescence intensity (MFI) of ${\mathrm{MHC}-\mathrm{II}^{+}}^{+}$ cells, DC transduction efficiency, proportion of DCs, cell surface marker expression and T cell MLR were analyzed by FlowJo 7.6 (FlowJo LLC). The procedure was repeated in triplicate.

Statistical analysis. Data were analyzed with one-way analysis of variance followed by a Student Newman Keuls-q post hoc test, or with a Pearson correlation analysis using SPSS 22.0
(IBM Corporation, Armonk, NY, USA). Data are presented as the means \pm standard deviation. $\mathrm{P}<0.05$ was considered to indicate a statistically significant difference.

\section{Results}

Lenti-shRNA-Blimpl exhibits high transduction efficiency in pre-DCs. The cells demonstrated green fluorescence on day 3 following lenti-shRNA-Blimp1 gene transduction (day 4 of culture), and its intensity gradually increased, exhibiting continuous GFP protein expression (Fig. 1A). The transduction efficiency was calculated as the proportion of $\mathrm{GFP}^{+}$ cells by flow cytometry. The values were $60.83 \pm 1.39$ and $60.64 \pm 0.65 \%$ in the lenti-Blimp1 and lenti-control groups ( $n=3 /$ group), respectively. No significant differences were observed with regards to the transduction efficiency between the two groups (Fig. 1B). No green fluorescence was detected in the empty-control group.

Lenti-shRNA-Blimpl gene transduction downregulates Blimpl expression. A total of $72 \mathrm{~h}$ post-transduction, the cells were harvested in order to assess the mRNA expression levels of Blimp1, CIITA and c-myc (Fig. 2A). The RQ values of Blimp1 mRNA were 0.59 $\pm 0.16,7.69 \pm 0.02$ and $7.33 \pm 0.28$ in the lenti-shRNA-Blimp1, lenti-control and empty-control groups ( $\mathrm{n}=3 /$ group), respectively $(\mathrm{P}<0.01)$. The RQ values of CIITA mRNA were $2.29 \pm 0.35,2.71 \pm 0.03$ and $2.71 \pm 0.02$, respectively $(\mathrm{P}>0.05)$. The RQ values of $\mathrm{c}-\mathrm{myc} \mathrm{mRNA}$ were $1.20 \pm 0.11,1.50 \pm 0.01$ and $1.16 \pm 0.06$, respectively $(P>0.05)$.

A total of $96 \mathrm{~h}$ post-transduction, the cells were harvested in order to examine the protein expression levels of Blimp1, and its direct target proteins CIITA and c-myc (Fig. 2B). The relative protein expression levels of Blimp1 in the lenti-shRNA-Blimp1, lenti-control and empty-control groups were $0.09 \pm 0.01,0.24 \pm 0.01$ and $0.35 \pm 0.05$ $(\mathrm{n}=3$ /group), respectively $(\mathrm{P}<0.05)$. The relative protein expression levels of CIITA were $1.53 \pm 0.16,1.08 \pm 0.12$ and $0.97 \pm 0.08$, respectively $(\mathrm{P}<0.05)$. The relative expression protein levels of $\mathrm{c}-\mathrm{myc}$ were $1.00 \pm 0.12,0.54 \pm 0.09$ and $0.67 \pm 0.08$, respectively $(\mathrm{P}<0.05)$ (Fig. $2 \mathrm{~B})$. Furthermore, the relative expression levels of IL-6, which is another direct target protein of Blimp1, were as follows: $18.20 \pm 0.57 \times 10^{3}$, $5.52 \pm 2.38 \times 10^{3}$ and $7.92 \pm 1.13 \times 10^{3} \mathrm{pg} / \mathrm{ml}$, respectively $(\mathrm{P}<0.01$; Fig. 2C). Furthermore, a significant correlation was identified between Blimp1 and CIITA, c-myc and IL-6 expression, with the following r-values: $-0.819,-0.622$ and -0.745 , respectively.

Lenti-shRNA-Blimpl gene transduction has no effect on the differentiation of bone marrow cells to DCs. On day 8, the percentage of $\mathrm{CD} 11 \mathrm{c}^{+} \mathrm{MHC}^{-\mathrm{II}^{+}}$cells was $73.80 \pm 1.69$, $75.35 \pm 0.42$ and $68.97 \pm 1.23 \%$ in the lenti-shRNA-Blimp1, lenti-control and empty-control groups ( $n=3 /$ group), respectively (Fig. 3A). No significant differences $(\mathrm{P}>0.05)$ were observed between the lenti-shRNA-Blimp1 group and the two control groups.

Lenti-shRNA-Blimpl gene transduction induces a downregulation in MHC-II expression on DCs, whereas it has no effect on the expression levels of CD80/CD86 


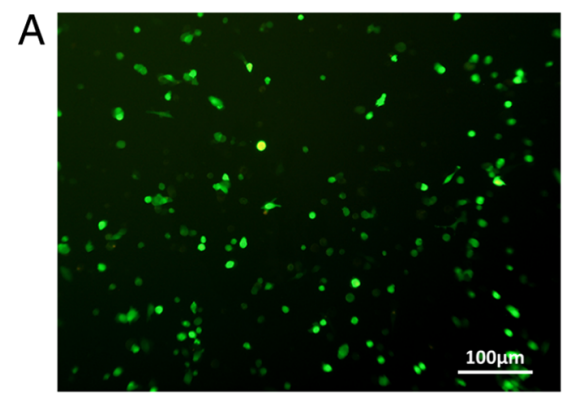

Day 4

B

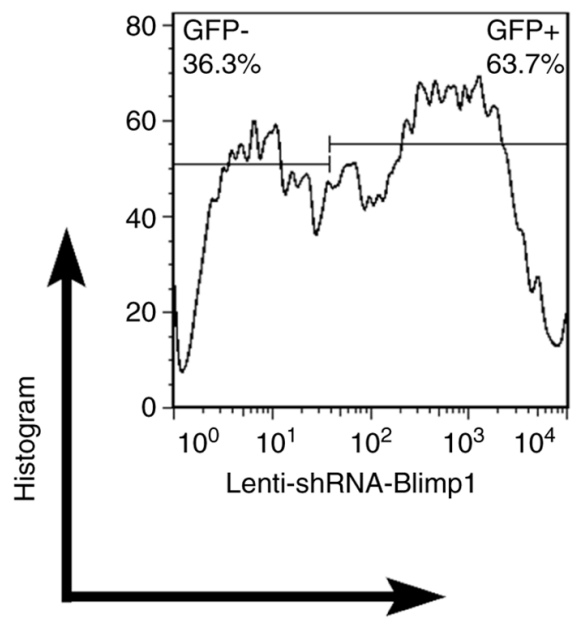

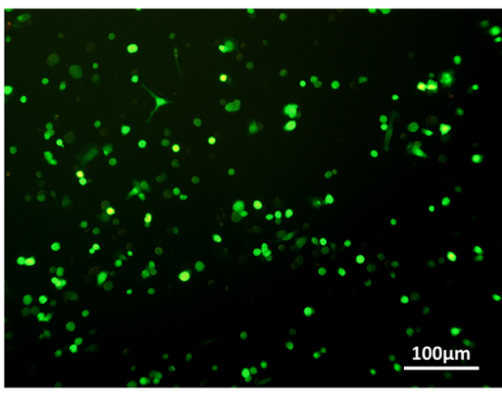

Day 5

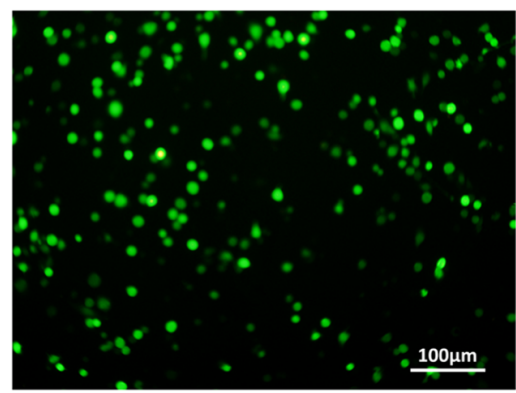

Day 6
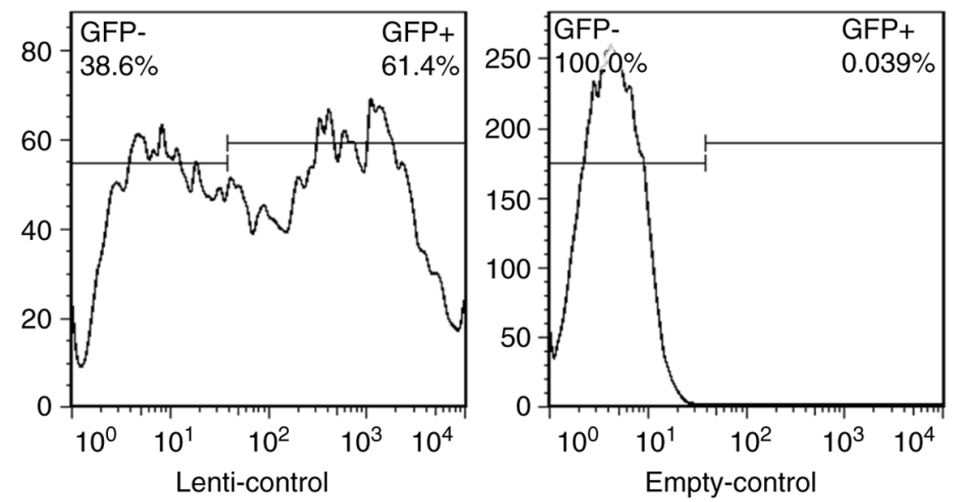

GFP

Transduction efficiency of lentivirus vector

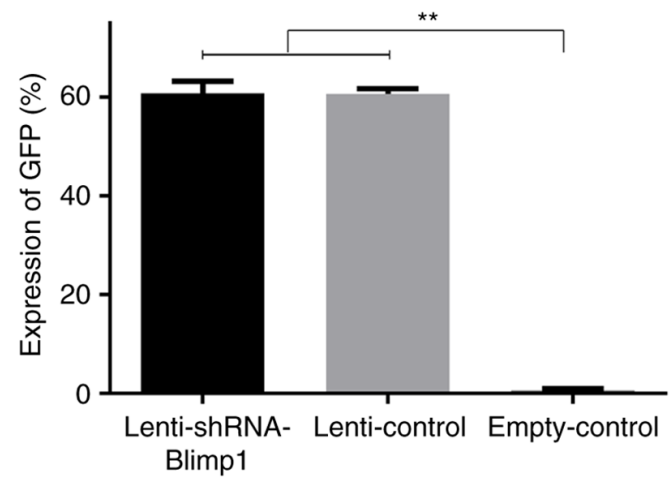

Figure 1. Transduction efficiency of lenti-shRNA-Blimp1 in DCs. (A) GFP expression in lentivirus-transduced cells. On day 1 of cell culture, the cells were transduced. GFP was detected on days 4, 5 and 6 (3,4 and 5 days post-transduction). Scale bar, $100 \mu \mathrm{m}$; magnification, $\mathrm{x} 200$. (B) Transduction efficiency was estimated as the proportion of $\mathrm{GFP}^{+}$cells, as determined by flow cytometry. $\mathrm{n}=3$ per group. ${ }^{* *} \mathrm{P}<0.01$. Blimpl, B lymphocyte-induced maturation protein-1; GFP, green fluorescent protein; shRNA, short hairpin RNA.

and $M H C-I$. With regards to antigen presentation, DCs transfer signals to $\mathrm{T}$ cells through signal 1 molecules (MHC-I/MHC-II) and signal 2 molecules (CD80/CD86).

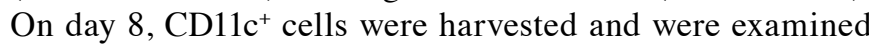
with regards to their maturation. The percentage of $\mathrm{MHC}-\mathrm{I}^{+}$ cells was $96.78 \pm 1.30,95.38 \pm 0.51$ and $96.46 \pm 0.75 \%$ in the lenti-shRNA-Blimp1, lenti-control and empty-control groups ( $\mathrm{n}=3 /$ group), respectively $(\mathrm{P}>0.05)$. The percentage of MHC-II ${ }^{+}$cells was $38.46 \pm 4.71,42.58 \pm 5.52$ and $54.48 \pm 3.67 \%$, respectively $(\mathrm{P}<0.05)$. MFI of $\mathrm{MHC}-\mathrm{II}^{+} \mathrm{DCs}$ was $393.50 \pm 9.19$, $478.00 \pm 31.11$ and $516.36 \pm 23.34$, respectively $(\mathrm{P}<0.05$; Fig. 3B). Furthermore, a significant correlation was identified between Blimp1 expression and the MFI of MHC-II, with an r-value of 0.966 (data not shown). The percentage of CD80 $0^{+}$ cells was $69.17 \pm 0.3,58.00 \pm 3.95$ and $60.30 \pm 1.01 \%$, and of $\mathrm{CD}^{+} 6^{+}$cells was $51.17 \pm 4.82,44.00 \pm 4.95$ and $51.30 \pm 0.91 \%$ in the lenti-shRNA-Blimp1, lenti-control and empty-control groups, respectively $(\mathrm{P}>0.05)$.

Stimulation by lenti-shRNA-Blimpl-transduced DCs alleviates alloreactive $T$ cell proliferation and induces Treg expansion. To clarify the effects of DCs on alloantigen presentation, alloreactive T cells were stimulated by DCs. At the end of the MLR, the proportion of divided alloreactive $\mathrm{T}$ cells in the empty-control group was $6.46 \pm 3.59$ under a DC:alloreactive T cell ratio of 1:10, compared with $18.05 \pm 0.92$ under a ratio of 1:5 (data not shown). Therefore, $2 \times 10^{4} \mathrm{DCs}$ were co-cultured with $1 \times 10^{5}$ alloreactive T cells in a 96-well 
A

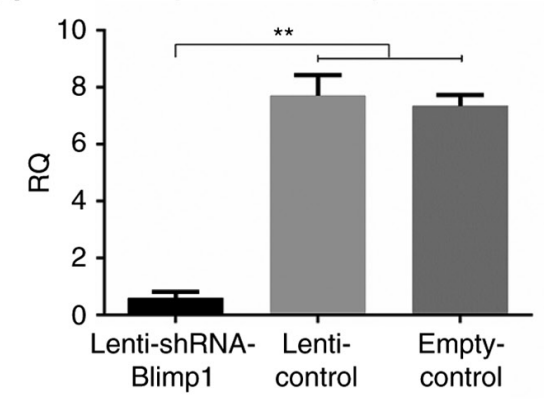

Expression of CIITA mRNA

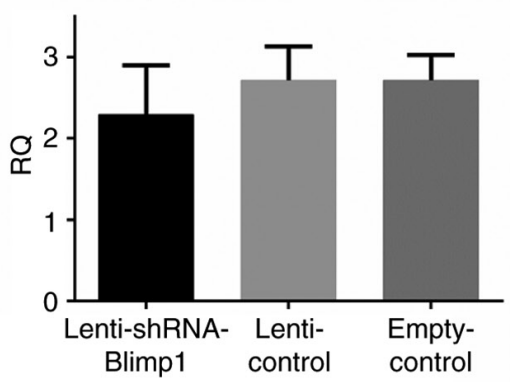

B
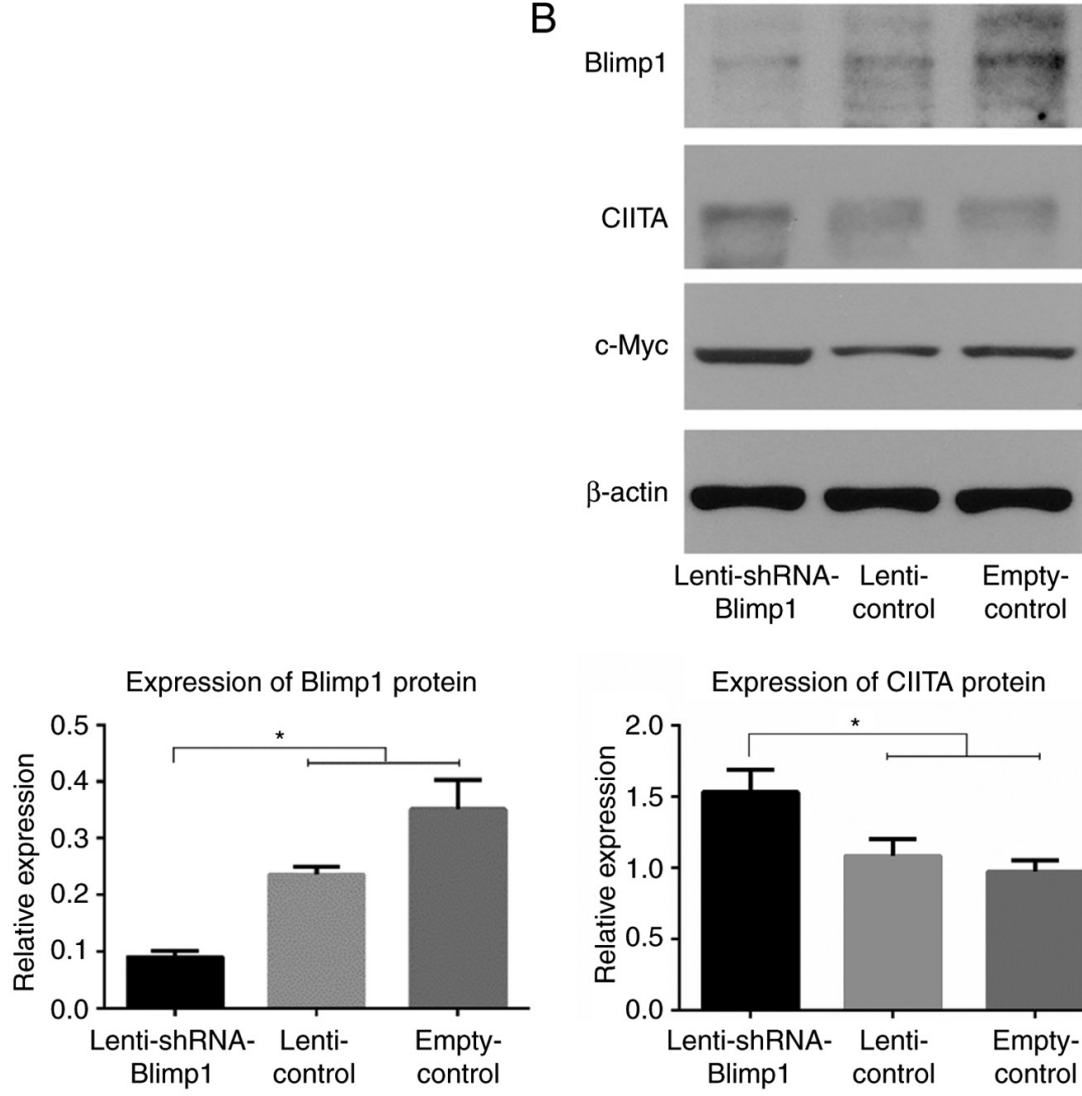

Expression of CIITA protein

Expression of Blimp1 protein

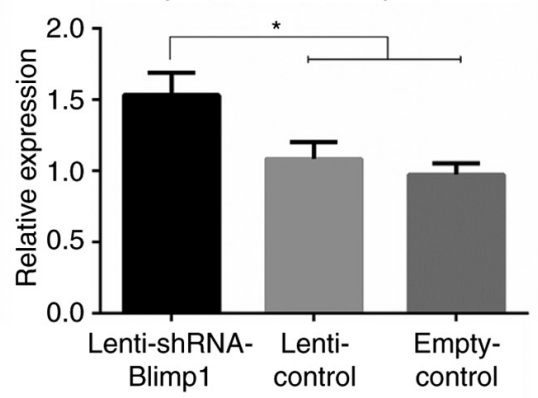

Expression of c-myc mRNA

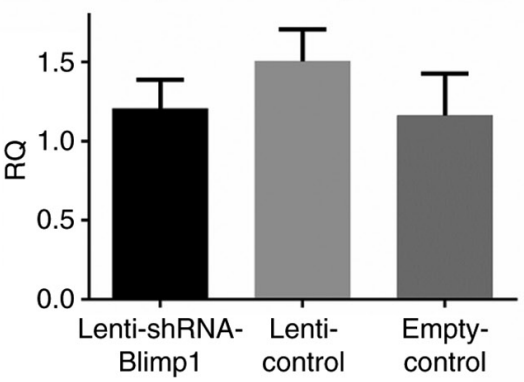

$95 \mathrm{kDa}$

$130 \mathrm{kDa}$

$60 \mathrm{kDa}$

$43 \mathrm{kDa}$

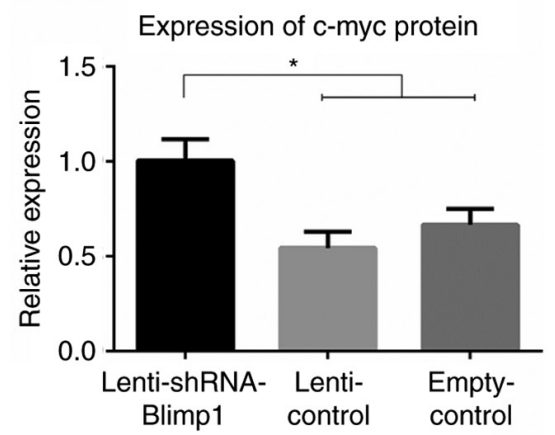

C

Expression of IL-6

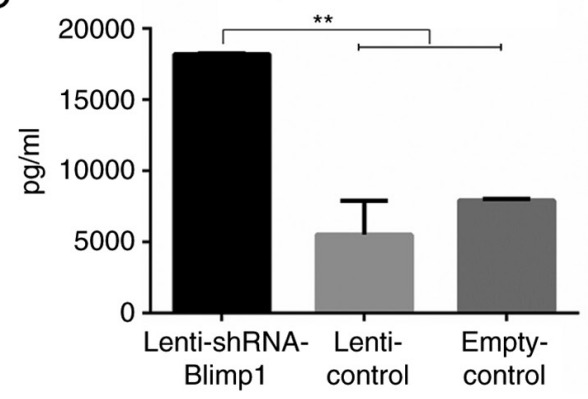

Figure 2. Lenti-shRNA-Blimp1 gene transduction downregulates the expression of Blimp1. (A) mRNA expression levels of Blimp1, CIITA and c-myc in cultured DCs $72 \mathrm{~h}$ following lentiviral transduction in the empty-control, lenti-control and lenti-shRNA-Blimp1 groups. (B) Protein expression levels of Blimp1, CIITA and c-myc in the cultured DCs $96 \mathrm{~h}$ following lentiviral transduction. (C) IL-6 levels in the supernatant $96 \mathrm{~h}$ following lentiviral transduction. $\mathrm{n}=3$ per group. ${ }^{*} \mathrm{P}<0.05 ;{ }^{* *} \mathrm{P}<0.01$. Blimp1, B lymphocyte-induced maturation protein-1; CIITA, class II major histocompatibility complex transactivator; IL-6, interleukin-6; shRNA, short hairpin RNA.

round-bottom plate. The proportion of divided $\mathrm{T}$ cells was $15.35 \pm 0.50,17.67 \pm 0.35,18.05 \pm 0.92$ and $54.32 \pm 0.82$ in the lenti-shRNA-Blimp1, lenti-control, empty-control and positive control groups (n=3/group), respectively (Fig. 4A).
Significant differences $(\mathrm{P}<0.05)$ were observed between the lenti-shRNA-Blimp1 group and all of the control groups.

The yield of Tregs was detected following stimulation of alloreactive $\mathrm{T}$ cells by DCs transduced with 

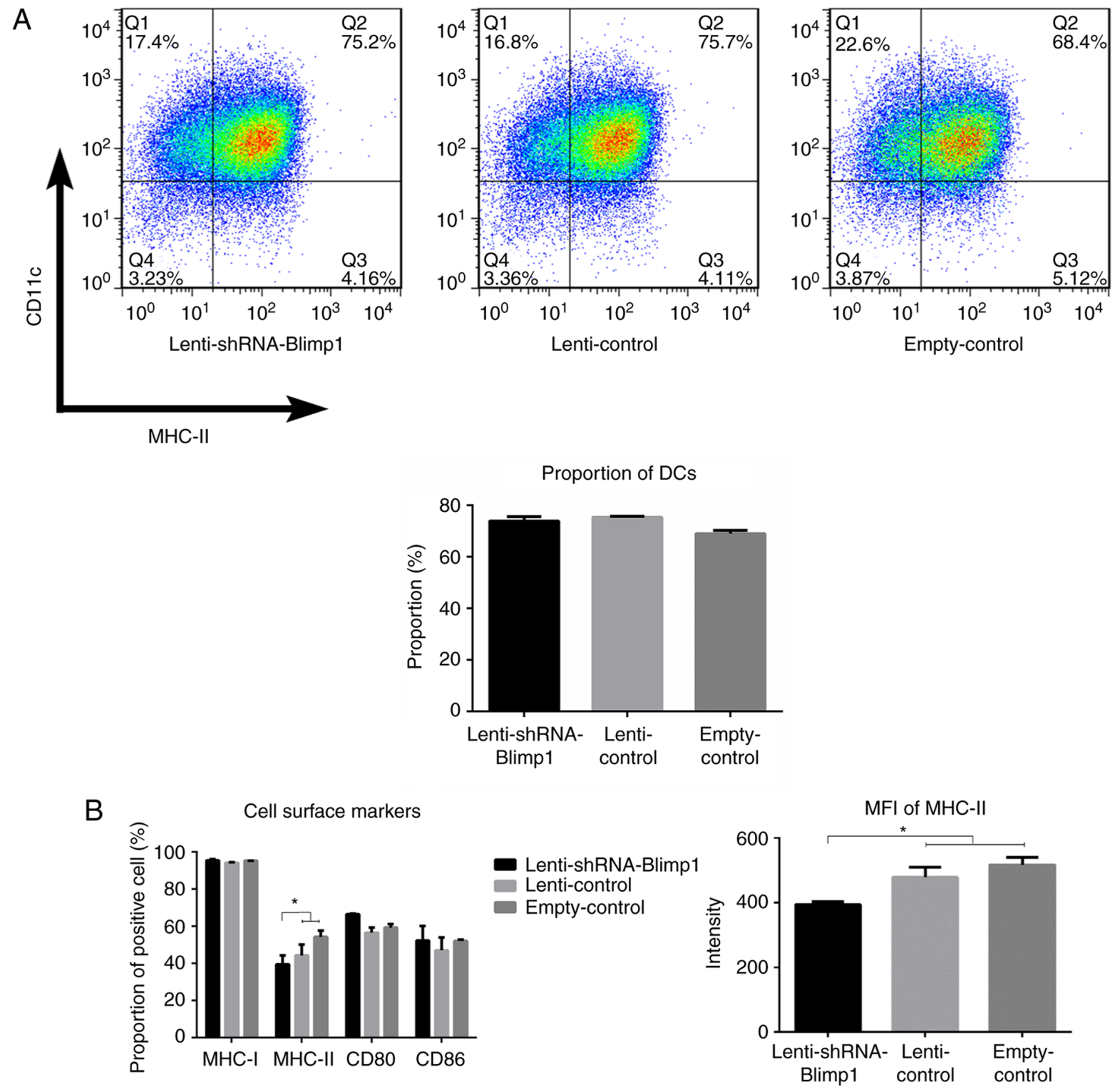

Figure 3. Lenti-shRNA-Blimp1 gene transduction exhibits no influence on the differentiation of DCs, although it inhibits their maturation. (A) Proportion of CD11 $\mathrm{c}^{+}$cells in the empty-control, lenti-control and lenti-shRNA-Blimpl groups at the end of culture (culture day 8). (B) Proportion of $\mathrm{MHCI}^{+}, \mathrm{MHCII}^{+}$, $\mathrm{CD} 80^{+}$and $\mathrm{CD} 6^{+}$cells in the groups. $\mathrm{n}=3$ per group. ${ }^{*} \mathrm{P}<0.05$. Blimp1, B lymphocyte-induced maturation protein-1; $\mathrm{CD}$, cluster of differentiation; $\mathrm{MFI}$, mean fluorescent intensity; MHC, major histocompatibility complex; shRNA, short hairpin RNA.

lenti-shRNA-Blimp1. The percentage of Tregs was $4.13 \pm 0.33$, $2.56 \pm 0.09$ and $2.62 \pm 0.26 \%$ in the lenti-shRNA-Blimp1, lenti-control and empty-control groups ( $\mathrm{n}=3$ /group), respectively. Significant differences $(\mathrm{P}<0.01)$ were observed between the lenti-shRNA-Blimp1 group and the control groups (Fig. 4B). Furthermore, a significant correlation was identified between Blimp1 expression and Tregs with an r-value of -0.719 , whereas the r-value between Blimp1 and divided T cells was 0.937 .

Lentiviral vectors cause mild damage to DC morphology. On culture day 2, cells in the empty-control group were round, granular and suspended in medium, whereas the number of adherent cells was increased. From day 2, the size of cells increased. On day 5 , the suspended cells were round, whereas the adherent cells were irregular in shape or spindle-shaped. On day 8 , the adherent cells reached $\sim 90 \%$ confluence, and were similar in size and morphology, and the majority of the cells had dendritic features. In the lenti-control and lenti-shRNA-Blimpl groups, certain fragmented cells appeared on day 2 and cell density was lower than that in the empty-control group. Subsequently, the suspended cells varied in size, and the adherent cells were irregular in shape and/or spindle-shaped. The morphology on day 6 is shown in Fig. 5A. Cells in the lenti-control and lenti-shRNA-Blimp1 groups exhibited similar morphological features.

Lentiviral vector, but not Blimpl, mildly suppresses the proliferation of DCs. Untransduced cells exhibited logarithmic growth within 3 days, and the highest number of cells $\left(1.26 \pm 0.33 \times 10^{6} /\right.$ well) was evident on day 4 . This number was decreased to $1.16 \pm 0.28 \times 10^{6} /$ well on day 6 , and was maintained at $1.13 \pm 0.23 \times 10^{6} /$ well on day 8 . Cells in both the lenti-control 
A
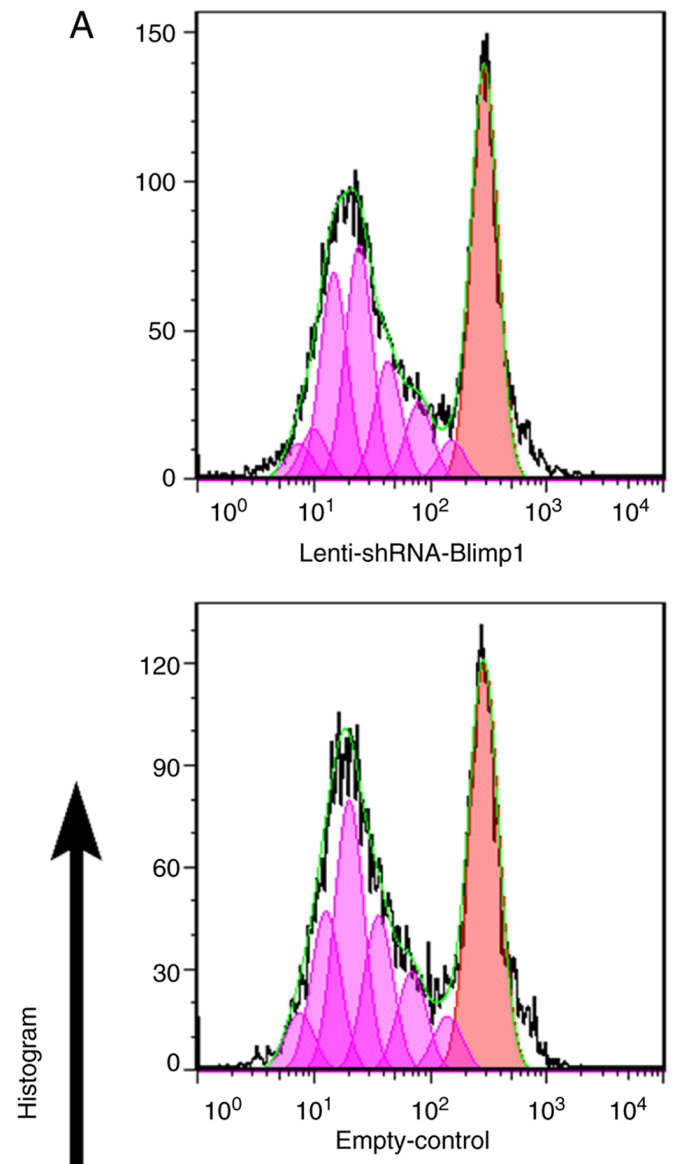
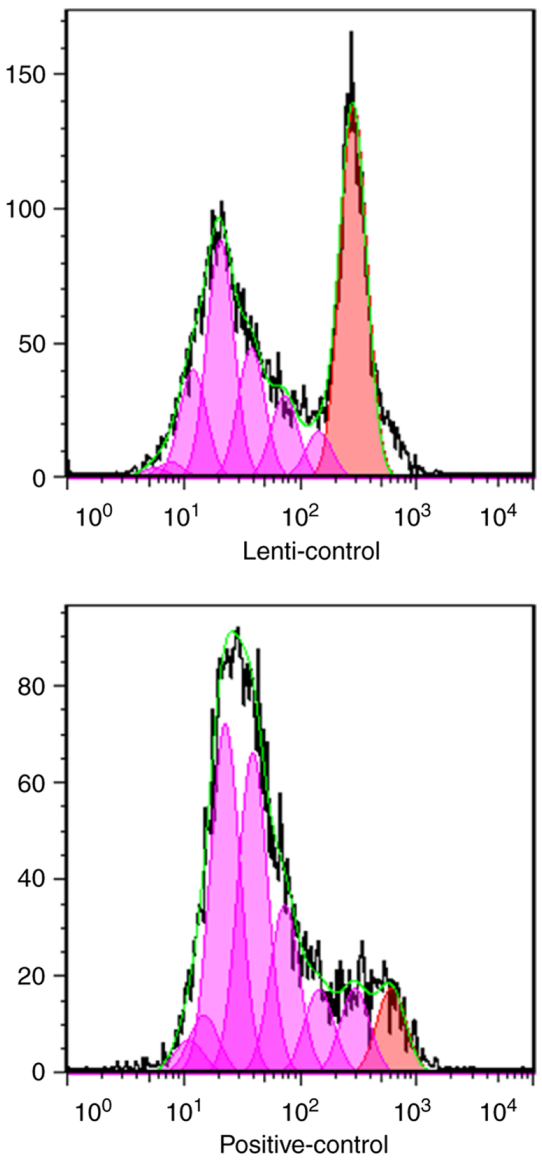

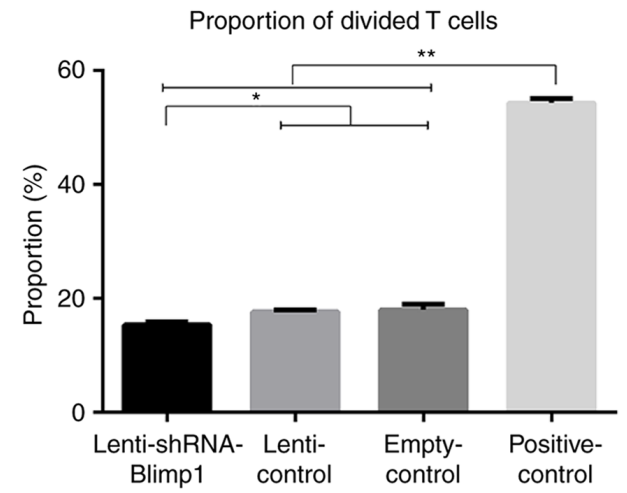

B

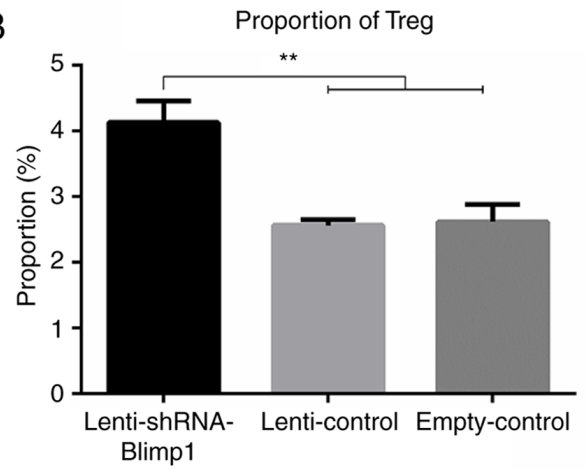

Figure 4. Lenti-shRNA-Blimp1 gene transduction alleviates alloreactive T-cell proliferation and expands Tregs. (A) Proportion of divided T cells was used to evaluate T-cell proliferation in the lenti-shRNA-Blimp1, lenti-control, empty-control and positive control groups. (B) Proportion of cluster of differentiation $4^{+}$forkhead box $\mathrm{P} 3^{+}$alloreactive $\mathrm{T}$ cells (Tregs). $\mathrm{n}=3$ per group. ${ }^{*} \mathrm{P}<0.05 ;{ }^{* *} \mathrm{P}<0.01$. Blimp1, B lymphocyte-induced maturation protein-1; shRNA, short hairpin RNA; Tregs, regulatory T cells. 
A

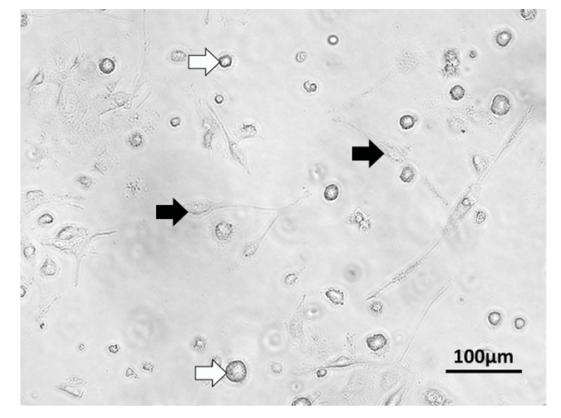

Lenti-shRNA-Blimp1

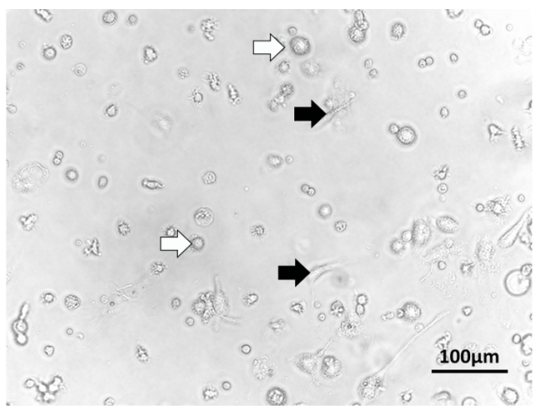

Lenti-control

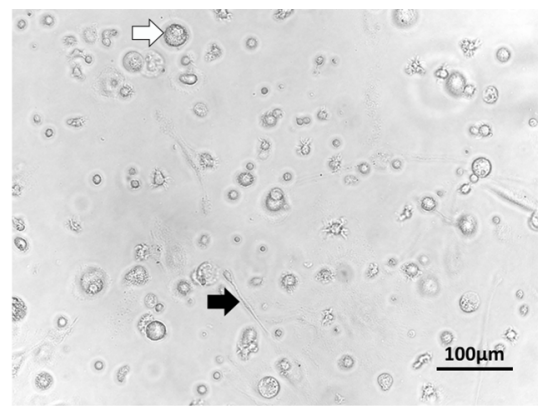

Empty-control

B

Number of cells per well

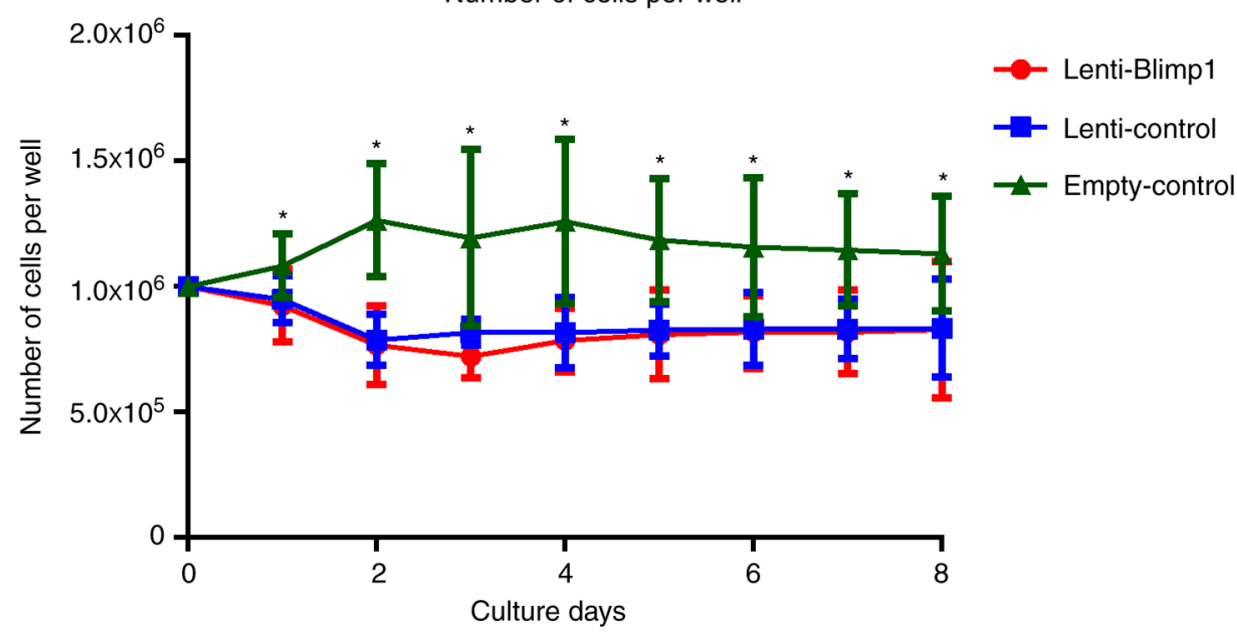

Figure 5. Lentiviral vector exerts mild toxicity on DCs. (A) Morphology of cultured DCs on day 6 in the empty-control, lenti-control and lenti-shRNA-Blimp1 groups. Suspended cells are indicated by white arrows, and adherent cells are indicated by black arrows. Scale bar, $100 \mu \mathrm{m}$; magnification, x200. (B) Proliferative curve of cultured cells. The cell number was counted in each well between days 1 and $8 . n=6$ per group. ${ }^{*} \mathrm{P}<0.05$. Blimpl, B lymphocyte-induced maturation protein-1; DCs, dendritic cells; shRNA, short hairpin RNA.

and lenti-shRNA-Blimp1 groups did not proliferate further on day 2 and all remained at a level $<0.83 \pm 0.19 \times 10^{6} /$ well (Fig. 5B). A significant difference $(\mathrm{P}<0.05)$ was obtained following comparison of the lenti-control and lenti-shRNA-Blimp1 groups with the empty-control group. The detection procedure was repeated six times. No significant difference $(\mathrm{P}>0.05)$ was noted between the lenti-control and lenti-shRNA-Blimp1 groups.

\section{Discussion}

DCs have been recognized as pivotal elements in the determination of either an immunogenic or tolerogenic effect, according to their mature states $(37,38)$. The establishment of a reliable culture system for the generation and manipulation of DCs is required to serve as a cornerstone for immunological studies $(23-26,34,38)$. It is well known that large numbers of myeloid-derived DCs can be generated from bone marrow cultures. The present study used an 8-day DC culture system derived from bone marrow cells (22). On day 3, all of the non-adherent cells were discarded, since the suspended cells consisted of heterogeneous clusters including granulocytes, red blood cells and DCs, whereas the adherent cells consisted mainly of pre-DCs. Removing the suspended cells from the culture decreased the yield but increased the final purity of the DCs; this is a key procedure performed at various time points (from hour 3 to day 4) in different protocols (22-26). On day 6, both non-adherent and adherent cells predominantly consisted of DCs and therefore were restored for further culture under LPS stimulation for maturation. The present strategy is reasonable and operable with a superior final DC yield of $1-1.5 \times 10^{8}$ DCs raised from a single mouse, a number 20-30 folds higher than that reached in previous studies $(22,25,34)$. Based on this procedure, bone marrow cells were induced to differentiate into pre-DCs and DCs with a large yield.

Lentiviral-mediated Blimp1-shRNA gene transduction was used to effectively downregulate Blimp1 expression in DCs. Firstly, it was verified that the lentiviral vector had a high efficiency to transduce bone marrow cells. GFP was detected 3 days post-transduction and was noted in $\sim 60.83 \pm 1.39 \%$ cells 8 days post-transduction in both the lenti-control and lenti-shRNA-Blimp1 groups. Furthermore, Blimp1 expression levels were detected in pre-DCs that were transduced with lenti-shRNA-Blimp1. The RQ of Blimp1 mRNA was reduced to $8.0 \%(0.59 / 7.33) 72 \mathrm{~h}$ post-transduction, which suggested that RNA interference was successful. Following $24 \mathrm{~h}$ of incubation, the relative protein expression levels of Blimp1 were downregulated to $22.5 \%(0.09 / 0.40)$ of the normal level. To date, Blimp1 has been identified as an essential factor for cell growth, and it has been reported that, in mammals, complete Blimp1 knockout leads to mortality (5). Therefore, lenti-shRNA-Blimp1 transduction was used for the 
immunological modulation of DCs as an appropriate strategy to partially downregulate Blimp1 expression. The present study further detected the expression levels of downstream target proteins of Blimp1, namely CIITA, c-myc and IL-6 (39-41), demonstrating that the expression of these proteins was regulated accordingly. Notably, this modulation may be a post-transcriptional effect, since the mRNA expression levels of these target proteins were stable in the presence and/or absence of lenti-shRNA-Blimp1. Collectively, these findings confirmed the efficiency and safety of lenti-shRNA-Blimp1 transduction.

The present study demonstrated that the decreasein Blimp1 expression had no effect on the committed differentiation of DCs. At the end of the culture procedure, the proportion of $\mathrm{CD} 11 \mathrm{c}^{+}$cells in the lenti-control and lenti-shRNA-Blimp1 groups indicated no difference compared with in the empty-control group. However, downregulation of Blimp1 during the differentiation process from bone marrow cells to DCs exhibited an impact on the maturation of DCs. The expression of MHC-II, but not MHC-I, molecules on the surface membrane of DCs was significantly decreased by lenti-shRNA-Blimp1 gene transduction, thus indicating the immature status of the cultured DCs. The process of antigen presentation to T-cell receptors (signal 1) may be hampered by the decreased amount of MHC-II molecules on the surface membrane of immature DCs, which may result in inactivation of antigen-specific alloreactive $\mathrm{T}$ cells. Notably, the expression of the co-stimulatory molecules CD80 and CD86 were not affected, thus suggesting that the inactivation of alloreactive $\mathrm{T}$ cells was not mediated via a co-stimulatory (signal 2) mechanism. Subsequently, MLR was employed to examine the effects of the induced immature DCs; the results revealed that alloreactive $\mathrm{T}$ cell proliferation was alleviated following stimulation of cells with lenti-shRNA-Blimp1-transduced DCs compared with non-transduced DCs. Furthermore, $\mathrm{CD}^{+}{ }^{+} \mathrm{FoxP}^{+}$Tregs were expanded following stimulation by immature DCs, which may partly contribute to the alteration in alloreactive $\mathrm{T}$ cell proliferation. Taken together, these data indicated that lenti-shRNA-Blimp1 gene transduction inhibited DC maturation via MHC-II molecule suppression, which in turn inhibited the subsequent alloreactive $\mathrm{T}$ cell reaction.

In the present study, lentiviral vectors exhibited mild toxicity on DCs during culture. Without intervention, the cultured cells exhibited a marked increase in burr-like protrusions, changed from a circular to dendritic morphology, and reached $90 \%$ confluence by the end of cell culture. Lentiviral transduction, either with lenti-vector or lenti-shRNA-Blimp1, induced variations in size and irregular shapes, with a decreased density in certain types of cells. Furthermore, the proliferation curves demonstrated that the cell number was slightly lower following lentiviral transduction compared with in cultures without intervention. Lenti-vector and lenti-shRNA-Blimp1 transduction arrested proliferation of DCs at similar levels, thus suggesting that the toxicity was derived from the lentiviral vector itself, and not Blimp1 shRNA. The toxicity of the lentiviral vector on DCs, although mild, requires further technical improvement. Furthermore, additional caution should be exercised with regards to the biosecurity of the lentivirus (42-44).
In conclusion, lenti-shRNA-Blimp1 transduction was able to modulate the maturation of DCs via the suppression of MHC-II molecules, and inhibited the subsequent alloreactive $\mathrm{T}$ cell activation. The findings of the present study support a Blimp1-based intervention as a novel approach and mechanism for inducing immature DCs, which may be adopted for certain aims, such as modulating the immunological alloreaction of $\mathrm{T}$ cells.

\section{Acknowledgements}

Not applicable.

\section{Funding}

The present study was supported by grants to NQ Gong from the National Natural Science Foundation of China (grant no. 81570678 and 81072441), the Major State Basic Research Development Program of China (grant no. 2013CB530803) and the Clinical Research Physician Program of Tongji Medi cal College, HUST.

\section{Availability of data and materials}

The datasets used and/or analyzed during the current study are available from the corresponding author on reasonable request.

\section{Authors' contributions}

NG and JS designed the experiments. JX, JZ, XL, XD, JW, LW and $\mathrm{YH}$ performed the experiments and analyzed the data. NG and JX wrote the paper. JX and JZ contributed equally to the present study. All authors read and approved the final manuscript.

\section{Ethics approval and consent to participate}

All experiments were approved by the Institutional Animal Care and Use Committee at Tongji Medical College, Huazhong University of Science and Technology (ethical approval no. TJ-A201111211).

\section{Patient consent for publication}

Not applicable.

\section{Competing interests}

The authors declare that they have no competing interests.

\section{References}

1. Mossink MH, de Groot J, Van Zon A, Fränzel-Luiten E, Schoester M, Scheffer GL, Sonneveld P, Scheper RJ and Wiemer EA: Unimpaired dendritic cell functions in MVP/LRP knockout mice. Immunology 110: 58-65, 2003.

2. Steinman RM, Inaba K, Turley S, Pierre P and Mellman I: Antigen capture, processing, and presentation by dendritic cells: Recent cell biological studies. Hum Immunol 60: 562-567, 1999.

3. Ying W, Fei H, Jun D, Xi-chuan Y, Bai-yu Z and Qing-yi Y: Reversible transfection of human melanocytes mediated by Cre/loxP site-specific recombination system and SV40 large T antigen. Exp Dermatol 16: 437-444, 2007.

4. Martins G and Calame K: Regulation and functions of Blimp-1 in T and B lymphocytes. Annu Rev Immunol 26: 133-169, 2008. 
5. Minnich M, Tagoh H, Bönelt $\mathrm{P}$, Axelsson E, Fischer $\mathrm{M}$, Cebolla B, Tarakhovsky A, Nutt SL, Jaritz M and Busslinger M: Multifunctional role of the transcription factor Blimp-1 in coordinating plasma cell differentiation. Nat Immunol 17: 331-343, 2016.

6. Martins GA, Cimmino L, Shapiro-Shelef M, Szabolcs M, Herron A, Magnusdottir E and Calame K: Transcriptional repressor Blimp-1 regulates T cell homeostasis and function. Nat Immunol 7: 457-465, 2006.

7. Magnúsdóttir E, Kalachikov S, Mizukoshi K, Savitsky D, Ishida-Yamamoto A, Panteleyev AA and Calame K: Epidermal terminal differentiation depends on B lymphocyte-induced maturation protein-1. Proc Natl Acad Sci USA 104: 14988-14993, 2007.

8. Lin FR, Kuo HK, Ying HY, Yang FH and Lin KI: Induction of apoptosis in plasma cells by B lymphocyte-induced maturation protein-1 knockdown. Cancer Res 67: 11914-11923, 2007.

9. Chan YH, Chiang MF, Tsai YC, Su ST, Chen MH, Hou MS and Lin KI: Absence of the transcriptional repressor Blimp-1 in hematopoietic lineages reveals its role in dendritic cell homeostatic development and function. J Immunol 183: 7039-7046, 2009.

10. Kurimoto K, Yamaji M, Seki Y and Saitou M: Specification of the germ cell lineage in mice: A process orchestrated by the PR-domain proteins, Blimp1 and Prdm14. Cell Cycle 7: 3514-3518, 2008

11. Takahashi $\mathrm{K}$ and Yamanaka S: Induction of pluripotent stem cells from mouse embryonic and adult fibroblast cultures by defined factors. Cell 126: 663-676, 2006.

12. Kim SJ, Zou YR, Goldstein J, Reizis B and Diamond B Tolerogenic function of Blimp-1 in dendritic cells. J Exp Med 208: 2193-2199, 2011.

13. Yang H, Qiu Q, Gao B, Kong S, Lin Z and Fang D: Hrd1-mediated BLIMP-1 ubiquitination promotes dendritic cell MHCII expression for CD4 T cell priming during inflammation. J Exp Med 211: 2467-2479, 2014.

14. Kim SJ, Gregersen PK and Diamond B: Regulation of dendritic cell activation by microRNA let-7c and BLIMP1. J Clin Invest 123: 823-833, 2013.

15. Datiles MJ, Johnson EA and Mccarty RE: Inhibition of the ATPase activity of the catalytic portion of ATP synthases by cationic amphiphiles. Biochim Biophys Acta 1777: 362-368, 2008.

16. Min Kim J, Young Choi J, Sun Kim M and Chang Kim S: In vivo excision and amplification of large human genomic segments using the Cre/loxP -and large T antigen/SV40 ori -mediated machinery. J Biotechnol 110: 227-233, 2004.

17. Ashihara E, Kawata $E$ and Maekawa T: Future prospect of RNA interference for cancer therapies. Curr Drug Targets 11: 345-360, 2010

18. Rubinson DA, Dillon CP, Kwiatkowski AV, Sievers C, Yang L, Kopinja J, Rooney DL, Zhang M, Ihrig MM, McManus MT, et al: A lentivirus-based system to functionally silence genes in primary mammalian cells, stem cells and transgenic mice by RNA interference. Nat Genet 33: 401-406, 2006.

19. Picanco-Castro V, de Sousa Russo-Carbolante EM and Tadeu Covas D: Advances in lentiviral vectors: A patent review. Recent Pat DNA Gene Seq 6: 82-90, 2012.

20. Escors D and Breckpot K: Lentiviral vectors in gene therapy: Their current status and future potential. Arch Immunol Ther Exp (Warsz) 58: 107-119, 2010

21. Watt FM and Hogan BL: Out of Eden: Stem cells and their niches. Science 287: 1427-1430, 2000.

22. Wang J, Zhao LB, Chang S, Ming CS, Yang J and Gong NQ: Dynamic changes of phenotypes and secretory functions during the differentiation of pre-DCs to mature DCs. J Huazhong Univ Sci Technolog Med Sci 37: 191-196, 2017.

23. Wheat WH, Pauken KE, Morris RV and Titus RG: Lutzomyia longipalpis salivary peptide maxadilan alters murine dendritic cell expression of CD80/86, CCR7 and cytokine secretion and reprograms dendritic cell-mediated cytokine release from cultures containing allogeneic T cells. J Immunol 180 8286-8298, 2008.

24. Machen J, Harnaha J, Lakomy R, Styche A, Trucco M and Giannoukakis N: Antisense oligonucleotides down-regulating costimulation confer diabetes-preventive properties to nonobese diabetic mouse dendritic cells. J Immunol 173: 4331-4341, 2004.

25. Inaba K, Inaba M, Romani N, Aya H, Deguchi M, Ikehara S, Muramatsu S and Steinman RM: Generation of large numbers of dendritic cells from mouse bone marrow cultures supplemented with granulocyte/macrophage colony-stimulating factor. J Exp Med 176: 1693-1702, 1992.
26. Lutz MB, Kukutsch N, Ogilvie AL, Rössner S, Koch F, Romani N and Schuler G: An advanced culture method for generating large quantities of highly pure dendritic cells from mouse bone marrow. J Immunol Methods 223: 77-92, 1999.

27. Brasel K, De Smedt T, Smith JL and Maliszewski CR: Generation of murine dendritic cells from flt3-ligand-supplemented bone marrow cultures. Blood 96: 3029-3039, 2000.

28. Gallucci S, Lolkema M and Matzinger P: Natural adjuvants: Endogenous activators of dendritic cells. Nat Med 5: 1249-1255, 1999.

29. Tooze RM, Stephenson S and Doody GM: Repression of IFN-gamma induction of class II transactivator: A role for PRDM1/Blimp-1 in regulation of cytokine signaling. J Immunol 177: 4584-4593, 2006.

30. Islam MF, Watanabe A, Wong L, Lazarou C, Vizeacoumar FS, Abuhussein O, Hill W, Uppalapati M, Geyer CR and Vizeacoumar FJ: Enhancing the throughput and multiplexing capabilities of next generation sequencing for efficient implementation of pooled shRNA and CRISPR screens. Sci Rep 7: 1040,2007

31. Galluzzi L, Ceccarelli M, Diotallevi A, Menotta M and Magnani M: Real-time PCR applications for diagnosis of leishmaniasis. Parasit Vectors 11: 273, 2018.

32. Wu RC, Chen DF, Liu MJ and Wang Z: Dual effects of cycloheximide on U937 apoptosis induced by its combination with VP-16. Biol Pharm Bull 27: 1075-1080, 2004.

33. O'Sullivan AM, O'Callaghan YC, O'Grady MN, Queguineur B, Hanniffy D, Troy DJ, Kerry JP and O'Brien NM: In vitro and cellular antioxidant activities of seaweed extracts prepared from five brown seaweeds harvested in spring from the west coast of Ireland. Food Chem 126: 1064-1070, 2011.

34. Wang J, Dai X, Hsu C, Ming C, He Y, Zhang J, Wei L, Zhou P, Wang CY, Yang J and Gong N: Discrimination of the heterogeneity of bone marrow-derived dendritic cells. Mol Med Rep 16: 6787-6793, 2017

35. Marelli-Berg FM, Hargreaves RE, Carmichael P, Dorling A, Lombardi $G$ and Lechler RI: Major histocompatibility complex class II-expressing endothelial cells induce allospecific nonresponsiveness in naive T cells. J Exp Med 183: 1603-1612, 1996.

36. Wallace PK and Muirhead KA: Cell tracking 2007: A proliferation of probes and applications. Immunol Invest 36: 527-561, 2007.

37. Banchereau J and Steinman RM: Dendritic cells and the control of immunity. Nature 392: 245-252, 1998.

38. Beriou G, Moreau A and Cuturi MC: Tolerogenic dendritic cells: Applications for solid organ transplantation. Curr Opin Organ Transplant 17: 42-47, 2012.

39. Wang P, Xue Y, Han Y, Lin L, Wu C, Xu S, Jiang Z, Xu J, Liu Q and Cao X: The STAT3-binding long noncoding RNA lnc-DC controls human dendritic cell differentiation. Science 344 : 310-313, 2014.

40. Yoon HS, Scharer CD, Majumder P, Davis CW, Butler R, Zinzow-Kramer W, Skountzou I, Koutsonanos DG, Ahmed R and Boss JM: ZBTB32 is an early repressor of the CIITA and MHC class II gene expression during B cell differentiation to plasma cells. J Immunol 189: 2393-2403, 2012.

41. Xia Y, Xu-Monette ZY, Tzankov A, Li X, Manyam GC, Murty V, Bhagat G, Zhang S, Pasqualucci L, Visco C, et al: Loss of PRDM1/BLIMP-1 function contributes to poor prognosis of activated B-cell-like diffuse large B-cell lymphoma. Leukemia 31: 625-636, 2017.

42. Kim SJ, Goldstein J, Dorso K, Merad M, Mayer L, Crawford JM, Gregersen PK and Diamond B: Expression of Blimp-1 in dendritic cells modulates the innate inflammatory response in dextran sodium sulfate-induced colitis. Mol Med 20: 707-719, 2015.

43. Muruve DA: The innate immune response to adenovirus vectors. Hum Gene Ther 15: 1157-1166, 2004.

44. Scanlon KJ: Cancer gene therapy: Challenges and opportunities. Anticancer Res 24: 501-504, 2004 